\title{
EL PAPEL DE HUMBOLDT EN EL ORIGEN Y DESARROLLO DE LA GEOGRAFIA MODERNA
}

\author{
HÉCTQR F. RUCINQUE ${ }^{1}$ \\ Universidad de Córdoba \\ Asociación Colombiana de Geógrafos (ACOGE). \\ WELLINGTON JIMÉNEZ ${ }^{2}$ \\ Sociedad de Ciencias Geográficas del Ecuador
}

No obstante los matices paradigmáticos, no pocas veces antagónicos, a los que suscriben diversas corrientes de la comunidad disciplinaria, o quizás por eso mismo, la geografía es una ciencia que ha alcanzado notable grado de madurez metodológica y filosófica. Su escenario de trabajo, la superficie terrestre, y su objeto de estudio, los fenómenos socio-culturales y físicobióticos asociados en interacción espacial, al igual que la manera como se enfoca ese estudio y las herramientas utilizadas para realizarlo, dan entidad a esta muy conspicua parcela especializada de la ciencia contemporánea. La definición y construcción teórica de la geografía se inició en el siglo XIX, gracias a un proceso intelectual innovador emprendido por unos cuantos estudiosos alemanes. Entre ellos, Alexander von Humboldt descuella con importancia singular, tanto por las precisiones metodológicas básicas que enunció, y por las técnicas de trabajo cuyo diseño y prueba le son acreditados, cuanto por su inmensa producción sustantiva y por el ascendiente de prestigio y autoridad erudita, que ayudaron a ganar para la geografía un espacio respetable en el mundo académico mundial. El propósito central del presente escrito busca hacer conciencia sobre los aportes de este científico al desarrollo moderno de la geografía, mediante la presentación de un sucinto bosquejo biográfico y, más particularmente, examinando la evidencia que puede hallarse en la exploración de sus obras. Los autores concordamos con la apreciación que la historia de la ciencia consigna sobre la multifacética personalidad científica de Humboldt, pero destacando el valor particular que tuvo como geógrafo, lo cual, en gran medida, sobrevive a su universalismo cosmográfico. Para nuestro entender, en estos años de bicentenario la revisión de los créditos que apoyan la putativa paternidad de Humboldt sobre la geografía científica no solo ayudan a justificarla y reafirmarla, sino que a los geógrafos debería enorgullecernos aun más porque tales créditos se basan en hechos que en perspectiva, lejos de apocarse con el paso del tiempo, se

* Algunas de las ideas desarrolladas en este trabajo fueron presentadas por el autor principal durante un seminario del Departamento de Geografía de la Universidad del Atlántico, Barranquiila, en noviembre de 1999. Otras, se incluirán para reflexión por el mismo autor en el texto de la conferencia inaugural del VII Coloquio de Geografía de la Unversidad del Cauca, Popayán (noviembre 7-9 de 2001), dedicado a conmemorar este nuevo Bicentenario de Humboldt. En la elaboración definitiva del artículo cuentan los aportes directos del profesor W. Jiménez, y las discusiones con él sostenidas a mediados del 2001, en Quito. Con nuestra interlocución, además, empezó a tomar forma un proyecto que, de hacerse realidad, sería el mejor tributo que geógrafo latinoamericano alguno pudiese hacer a la memoria humboldtiana.

1 DR. h.F. Rucinque es asesor científico de la Universidad de Córdoba, Montería, Colombia - GeoLatinAm.com, en materias geográficas. Es el Editor de GeoTrópico, una nueva revista electrónica identificada con la URL www.geotropico.org/. Correspondencia: GeoLatinAm, Apartado 84.977, Bogotá DC, Colombia, e-mail:hrucin @cable.net.com.

2 Prof. Wellignton Jiménez es el Presidente de la Sociedad de Ciencias Geográficas del Ecuador, Quito. Correspondencia: Calle Cacha 243, La Magdalena, Quito, Ecuador, e-mail: wjimenez10@hotmail.com. 
refinan con un hálito de predicción, que enaltece de incuestionable perpetuidad la figura del sabio.

En julio de 1999, en efecto, se cumplieron dos siglos desde el momento en que Alexander von Humboldt pisó por primera vez tierras del Nuevo Mundo en la localidad de Cumaná, Venezuela, como comienzo de un periplo científico por la América tropical que se prolongaría hasta 1804. el Barón prusiano contaba entonces con escasos 30 años de edad, pero, no obstante su juventud, venía precedido de una fama de científico consumado, la cual, por fuerza de sus reales méritos, proyectaba en el entorno intelectual una imagen de gran personaje. Poco tiempo después de explorar Venezuela y hacer su primera visita a Cuba, siguiendo la ruta obligada de aquel tiempo, o sea desembarcar en Cartagena, navegar Magdalena arriba y remontar los Andes, Humboldt llegaría a la capital del virreinato de la Nueva Granada, con la pompa que en adelante habría de acompañar todas sus llegadas y partidas. él mismo, en carta a su hermano Wilhelm, fechada el 21 de septiembre de 1801, calificaba su llegada a Santa Fe como parecida a "una marcha triunfal", pues se le había destacado una comisión de notables para recibirlo a la entrada de la Sabana, el arzobispo le había puesto a disposición su propio carruaje, y su arribo al centro de la ciudad fue escoltado por un séquito de más de 60 jinetes (Humboldt 1989: 74).

Que ello hubiese ocurrido en un medio tan provinciano y colonial como el de la Nueva Granada, al despuntar el siglo XIX, es suficientemente explicable. Pero que el paso inexorable de doscientos años no le haya hecho mella a la aureola del sabio naturalista sino que, al contrario, la acreciente, es algo que mueve a reflexión. Los rusos zaristas también distinguieron a Humboldt casi con veneración y le abrieron todos los caminos para estudiar Siberia y las montañas del Asia Central. Ello puede explicarse porque para la época de sus viajes a Rusia su fama y madurez científica carecían de rivales $\mathrm{y}$, sin duda, porque el ascendiente aristocrático de la familia Humboldt y la cercana vinculación de Alejandro con la corte prusiana, lo hacían bienvenido entre los monarcas reinantes. pero algo más debe haber sido tenido en cuenta por quienes, muchos años después y en un trasfondo no precisamente afecto a ninguna parafernalia cortesana, resolvieron dar el nombre de Mare Humboldtianum a una de las yermas planicies descubiertas por el Lunik III soviético, en la primera exploración de la cara oculta de la Luna, en 1959. Y eso que ya un cráter importante del satélite, anteriormente había sido distinguido con el nombre de Humboldt. De hecho, es pertinente anotar que el nombre de Humboldt ha sido utilizado para distinguir todo tipo de institutos de enseñanza, desde gimnasios elementales hasta dos universidades, centros de investigación y organismos de fomento científico. Entre éstos destaca la Fundación Alexander von Humboldt, constituida en 1860 con un pool de donaciones de la Real Sociedad de Londres, la Academia de Ciencias de San Petersburgo, el rey de Prusia y los industriales Borsig y Siemens.1 En obvia reiteración, Humboldt también es recordado en la nomenclatura geográfica, empezando por el nombre más familiar con el que se conoce la Corriente del Perú, el de uno de los más grandes glaciares de Groenlandia, un pico en Colorado, unas montañas en Nevada, un río y un lago en este mismo estado, una bahía en la Nueva Guinea indonesia, otra bahía en California, tres ciudades en Iowa, Tennessee y Saskatchewan, tres condados en los estados de Iowa, California y Nevada. Y así, sucesivamente, en otras localidades del mundo. en fin, pues, existen numerosos indicadores de que la memoria de los pueblos, no muy resistente al alzheimer histórico con el paso de los años, sigue rubricando impertérrita la permanencia de este sabio, quizás mucho por la inercia del prestigio ganada por él inicialmente y menos por el real conocimiento que de su obra tienen hoy el común de las gentes, muchos intelectuales y, ojalá no fuera así, hasta los geógrafos.

Como es de esperarse, de cuando en cuando, en ocasiones conmemorativas, el nombre de Humboldt asoma a la consideración erudita mundial, fenómeno que ahora se repite, 142 años después de su muerte. Sus hechos académicos y científicos se rememoran generalmente con reverencia, y las nuevas ediciones de sus obras asumen características de best-sellers, aunque a veces de todas maneras se necesita ser afortunado para encontrarlas disponibles en las librerías. Después de tanto tiempo, la vigencia de Humboldt sorprende. La voluminosa literatura humboldtiana - que incluye además viejas y nuevas biografías, y estudios críticos de su legado desde todos los puntos de vista imaginables - se enriquece cada día. La comunidad científica y académica pareciera como si estuviese atenta con anticipación a ciertos años, como los de 1959, 1969, 1999, para incrementar la productividad bibliográfica, ya sea con ocasión del centenario de 
su muerte, el bicentenario de su nacimiento, o el bicentenario del comienzo de su expedición a América. La muestra de la renovación de la literatura relativa a Humboldt es abultada en distintos idiomas, especialmente en alemán, inglés y francés. Y en español ocurre lo propio. Para el período de treinta años, transcurridos entre 1969 y 1999, se tiene un registro de 127 entradas selectas, lo que quiere decir que por fuera quedan sin reseñar innumerables artículos cortos y notas de periódicos y revistas generales (Hampe Martínez 1999). De seguro, de 1999 en adelante esa producción se habrá incrementado sustancialmente.

El ascendiente de que Humboldt disfrutó en su larga y fructífera vida científica fue de veras extraordinario, y ello puede haber ayudado a perpetuar la inusual dimensión de su figura. Concomitante con esto, sin duda ayudan la combinación afortunada del rigor científico con la belleza y claridad de la prosa que distingue sus escritos, accesibles a especialistas y profanos por igual. Otra indicio puede encontrarse en el sugestivo respaldo que Humboldt otorgó sin tapujos a las causas de reivindicación social y a las ideas liberales y democráticas. Y también puede hallarse una explicación plausible a esta permanente actualidad en el ámbito polifacético, universalista, de sus intereses científicos y saberes, lo cual desde el principio le atrajo seguidores —y también críticos - desde muchos campos disciplinarios.

¿Quién era y cuáles fueron las casas tan importantes que hizo Humboldt?

Una breve exploración biográfica puede ser de interés recordatorio para el lector y probablemente ayudará a comprender la fascinación que nuestro personaje despertó entre sus contemporáneos, tanta en el medio culto como en el pueblo raso, y contribuirá a poner en perspectiva su importancia para la comunidad geográfica, que es lo que se nos antoja pertinente para estos años de bicentenario. Las siguientes notas resumidas sobre la vida de Humboldt se basan en los recuentos de dos de sus biógrafos más conocidos, De Terra (1956) y Scurla (1982), a quienes se remite al lector interesado en detalles, aunque ciertamente la bibliografía humboldtiana es abundante en opciones para consulta adicional.

Para empezar, recordemos que Friedrich Wilhelm Heinrich Alexander von Humboldt nació en Berlín el 14 de septiembre de 1769 y murió longevo en la misma ciudad, el 6 de mayo de 1859 . La familia de Alexander, de estirpe aristocrática, estaba constituida por su padre Alexauder Georg von Humboldt (1720-79), un mayor buena gente del ejército de Federico el Grande de Prusia; por su madre, Frau Marie Elisabeth von Hollwege (1741-97), descendiente de hugonotes de Borgoña exiliados en Prusia desde el siglo anterior, heredera de apreciable fortuna de un matrimonio anterior; y por su hermano mayor Wilhelm (1767-1835). La infancia y temprana juventud de los hermanos Humboldt transcurrieron entre Tegel, pequeña aldea en donde la familia tenía su casa de campo, y Berlín, la capital prusiana. Helmut de Terra, el biógrafo de Alexander, describe así a esta ciudad:

Por entonces, Berlín era la cuarta parte del tamaño de París. Una urbe provinciana, con 150.000 habitantes aproximadamente. al igual que otras ciudades dieciochescas, era un lugar ruidosa y maloliente; sus calles estaban llenas de basura, de carros trepidantes, de mendigos y músicos ambulatorios; sus noches las hacían insomnes riñas de borrachos y canciones tristes de los serenos. Federico el Grande había hecho lo posible por dotar a Berlín de un núcleo de cultura italiana y francesa, de acuerdo con su preferencia por las ciencias y las letras francesas y por la música italiana. Desconfiaba de la cultura germánica. Nombró presidente de la Academia de Ciencias a Pierre-Louis Maupertius, un físico y matemático parisiense que había determinado el achatamiento terrestre en los polos. pero al hombre de la calle le importaba poco que este francófilo que ocupaba el trono gustara la compañía de excéntricos extranjeros, siempre y cuando persistiese en su proyecto de convertir a Berlín en un centro manufacturero de lanas, algodones y sedas.

Tempranamente huérfanos de padre, la formación de los hermanos Humboldt correspondió dirigirla a su madre Marie Elisabeth, descrita como mujer culta pero convencional, a quien faltaba calor y cordialidad, con poca o ninguna facilidad para demostrar amor por su familia, y aferrada a la idea de diseñar el futuro de sus hijos según la personal apreciación de lo que era mejor para ellos. Sin duda, proporcionó a Wilhelm y Alexander la mejor educación posible de la época, mediante tutores privados, imbuidos en las ideas pedagógicas de J.J. Rousseau (1712-78), como se estilaba entre las familias adineradas del país. Hay quienes sospechan que la devoción de toda 
una vida de Alexander por las ciencias, y su natural tozudez y persistencia en los proyectos, se debieron a la autosuficiencia que él tuvo que desarrollar en el frío ambiente familiar en el que le tocó empezar a vivir.

En la formación de Humboldt influyó poderosamente la Ilustración Berlinesa, un movimiento intelectual inspirado por el filósofo Moses Mendelssohn (1729-86), abuelo del compositor Félix Mendelssohn-Bartholdy (1809-47). La Ilustración prusiana estuvo muy estrechamente ligada con la comunidad judía. De aquella relación probablemente se derivó el sesgo de nuestro sabio aristócrata por las ideas de libertad e igualdad entre los hombres, lo cual se reforzaría después por su estrecha vinculación con la cultura parisina y por el torbellino renovador de la sociedad europea, en todos los órdenes, impuesto violentamente por las Revoluciones Americana y Francesa, y por los demás conflictos que vivió de cerca en el siguiente medio siglo.

Precisamente dos años antes de que París fuese sacudido por la irrupción de aquel proceso, los Humboldt iniciaron su formación universitaria, inicialmente en Frankfurt del Oder. Decepcionado de aquella primera experiencia universitaria, en menos de un año, en 1788, Alexander volvió a casa e hizo en Berlín algunos estudios de administración, para complacer a su madre. Ese año conoció y empezó una amistad de por vida con Carl Ludwig Willdenow (1765-1812), un reputado botánico que habría de impulsar aún más su devoción por las ciencias naturales. En 1789, Alexander fue a Gottingen, la más famosa universidad alemana de esos tiempos, en la cual caería dentro de la órbita de influencia de los profesores Johann Heinrich Blumenbach (17521849) y Christian Gottlob Heyne (1729-1812). Del primero recibió los estímulos para la observación directa de los fenómenos y los viajes de estudio, de los cuales, sobre un escenario estrictamente alemán resultaría su primer libro de mineralogía. A Heyne le adeudó su afición por la arqueología y la claridad crítica de los estudios históricos y sociológicos. Fue también por Heyne que Humboldt pudo conocer al yerno de aquél, Georg Forster (1754-1794), un botánico veterano de muchas travesías, entre ellas la de la vuelta al mundo con nadie menos que el capitán James Cook.

Forster - escribe el ya citado De Terra - había aparecido como un cometa en el firmamento académico de Gottingen, y el joven Humboldt fue lo suficientemente rápido para agarrarle la cola. Invitado o no, decidió acompañar a Forster en un viaje a Inglaterra. ¿Qué pasaría si se opusiese su madre? Podía ir, le escribió ésta, si al volver continuaba sus estudios de comercio en Hamburgo. Ella y su consejero Kunth no previeron con claridad lo que este viaje con Forster significaba para Alexander.

Aquel viaje se hizo en la primavera de 1790: observaciones sistemáticas de todo el contenido del paisaje a lo largo del Rin hasta Holanda; y de allí a Inglaterra. El regreso lo hicieron a través de la Francia revolucionaria, llegando a París a mediados de aquel año. De tan rica experiencia formativa cristalizaron tanto el decidido interés de Humboldt por la geografía y el trabajo científico de campo, como el fortalecimiento de sus ideas liberales, reafirmadas a través del entusiasmo con que Forster secundó el ideario revolucionario.2

La formación de Alexander prosiguió en la Academia Busch de Hamburgo, y luego, en 1791, en la Escuela de Minas de Freiburg, a donde ingresó atraído por la fama del equipo docente que presidía A. G. Werner (1749-1817), uno de los más famosos geólogos de la época; y también para buscar una especialización en administración minera, que eventualmente le permitiría ingresar al servicio público, aplacando los insistentes reclamos de su madre para que orientase su formación en tal sentido. Y, en efecto, Humboldt se emplearía en el Departamento Prusiano de Minas, en la sección correspondiente a Franconia, alcanzando en breve tiempo el rango de supervisor, el más alto cargo disponible. Su experiencia como funcionario del Estado fue muy provechosa, pues lo hizo percatarse de los problemas económicos asociados con la explotación minera, y proporcionó por otro lado la oportunidad de estudiar y buscar soluciones a los problemas sociales de los mineros. En 1793 publicó su primer trabajo científico importante, fruto de sus observaciones y experimentos relacionados con las plantas que crecen en los socavones.

La madre de Humboldt murió en 1796, y casi de inmediato él renunció a su puesto de supervisor de minas, para dedicarse a lo que siempre había tenido en mente: ser un hombre de ciencia. Tenía 27 años de edad, una buena formación en geología, botánica, geografía, astronomía, zoología, humanidades clásicas y el dominio de los idiomas inglés, español, francés e 
italiano. Era animoso y tenía a su disposición una herencia la suficientemente abultada para despreocuparse de la necesidad de trabajar para ganarse la vida. Además, contaba entre sus amigos a los mejores científicos de Europa. Era muy cercano de Johann Wolfgang von Goethe (1749-1832) y de Johann Christoph Friedrich von Schiller (1759-1805).

De entonces en adelante toda la dedicación de Humboldt se orientaría a prepararse para las expediciones científicas que tenía en mente desde hacía años. Hizo varios viajes que lo llevaron a Jena, Dresden, Viena y Salzburgo, acumulando el equipo que necesitaría para realizar sus observaciones con el mayor rigor y exactitud posibles. Con idéntico propósito, y también para revisar las colecciones botánicas allí existentes, viajó a París en 1798. En esa actividad tuvo ocasión de conocer a un joven botánico de nombre Aimé Jacques Alexandre Goujaud Bonpland (1773-1858), quien luego se constituiría en su muy valioso compañero de viaje al Nuevo Mundo. La decisión de viajar a América fue una fortuita alternativa que siguió Humboldt cuando sus planes originales de dirigirse al Norte de África quedaran en nada.

Humboldt y Bonpland optaron por ir a España, para buscar el permiso de la Corte que les permitiese visitar sus colonias de ultramar. En Madrid permanecieron desde febrero hasta mediados del año de 1799. Finalmente, portadores de pasaportes especiales, los dos científicos salieron del puerto de La Coruña el 5 de junio del penúltimo año del siglo XVIII, rumbo a las regiones equinocciales del Nuevo Continente. Como es de suponerse, Humboldt estaba en un estado de excitación extraordinario. En carta a un amigo de nombre Freiesleben, escribía:

Estoy aturdido de alegría. Zarpo en la fragata española Pizarro. Desembarcaremos en las islas Canarias, y en la costa de Caracas, en Sudamérica... Recogeré plantas y fósiles, y realizaré observaciones astronómicas con los mejores instrumentos. Trataré de averiguar como actúan las fuerzas de la naturaleza unas sobre otras, y de qué manera influye el ambiente geográfico en las plantas y en los animales. Resumiendo, lo que quiero es hacer observaciones acerca de la armonía en la naturaleza" (Humboldt, cit. por De Terra 1956: 75).

Un regocijo, en fin, casi tan cercano al éxtasis como el que lo embargó al encontrarse días después, el 16 de julio, en tierra americana. Así le escribió ese mismo día a su hermano desde Cumaná:

¿Qué árboles! Cocoteros de 50 a 60 pies de altura, la Poinciana pulcherrima con ramilletes de un pie de altura de flores de un rojo vivo magnífico; plátanos y una masa de árboles con hojas monstruosas y flores perfumadas de tamaño de una mano, del as que no sabemos nada... ¡Qué numerosas son también las plantas más pequeñas aún no examinadas! Y qué colares poseen los pájaros, los peces, hasta los cangrejos (azul cielo y amarillo)! Hasta ahora nos hemos paseado como locos... Bonpland asegura que se volverá loco si no terminan pronto de aparecer las maravillas. Pero lo que es más bello aún que estas maravillas vistas particularmente, es la impresión que produce el conjunto de esta naturaleza vegetal poderosa, exuberante, y sin embargo tan dulce, tan fácil, tan serena (Humboldt 1989: 14).

El itinerario y los trabajos cumplidos por Humboldt y su asistente en el Nuevo Mundo son de sobra conocidos y han sido descritos en detalle en numerosos escritas, incluidos, por supuesto, los del propio sabio. Pero vale la pena recordarlas en este bicentenario, así sea de manera muy resumida, pues todavía permanecen como un monumento de la investigación individual, y un ejemplo de la manera como un estudioso puede con método riguroso cubrir amplios escenarios y complejos problemas, para producir resultados de gran relevancia, en tiempo limitado.

Desde Cumaná, Humboldt se desplazó a varios puntos de la región andina venezolana, durante los últimas meses de 1799 y principios del siguiente año, haciendo todo tipo de registros, desde las condiciones de los esclavos negros, los cambios ocurridos en el lago Valencia, recolección y clasificación de infinidad de plantas y animales, hasta observaciones astronómicas, incluidos un eclipse solar y una gran lluvia de meteoritos. A partir de febrero de 1800 se adentró con Bonpland en los Llanos, rumbo al Orinoco. Navegando en canoa por el Apure, los viajeros llegaron al gran río, el cual remontaron hasta el Atabapo, corriente que los condujo a los afluentes próximos a la cuenca del Río Negro. Arrastrando la piragua por tierra, los cargadores los llevaron hasta afluentes de aquel río de la cuenca amazónica, por uno de los cuales navegaron hasta a unos $2^{\circ}$ de latitud del ecuador. Luego remontaron el Río Negro hasta encontrar el Casiquiare, cuya penosa y larga navegación les permitió comprobar la conexión natural entre las dos cuencas fluviales más 
importantes de Sudamérica. Otra vez navegando por el Orinoco, ahora aguas abajo, y luego de la demora ocasionada por la enfermedad de Bonpland, que estuvo a punta de morir en Angostura, los científicos retornaron a Cumaná el 1 de septiembre. Habían recorrido unas 6.400 millas a través de una de las regiones más inhóspitas de América. Escribe De Terra:

$\mathrm{Su}$ botín científico era fabuloso en datos, colecciones y mediciones por medio de instrumentos. Habían colectado veinte mil plantas, de las cuales clasificaron mil cuatrocientas en el camino... Habían realizado el primer corte transversal en la profusa riqueza vegetal de los trópicos americanos y les era posible aplicar el sistema de Lineo a miles de especies vegetales hasta entonces desconocidas (De Terra 1956: 92).

A fines de noviembre de 1800 Humboldt y Bonpland se embarcaron para Cuba, de cuyas observaciones tanto en la Habana como en varias partes de la isla resultaría el material suficiente para un ensayo memorable que se publicaría en 1828. Dicho sea de paso, la obra resultante, junta con otra de naturaleza similar escrita sobre México, son dos tratadas corográficos en las cuales Humboldt relacionó de manera coherente y analítica los aspectos físicos (geología, topografía, clima) con los culturales (comercio, comunicaciones, población, renta).

El regreso al subcontinente sudamericano lo hizo Humboldt por Cartagena, a donde arribó el 30 de marzo de 1801. Vacilando entre tomar desde allí una ruta marítima hacia Guayaquil, a través del istmo de Panamá, o viajar por tierra a través de la Nueva Granada y de paso visitar en Santa Fe de Bogotá a don José Celestino Mutis —el Lineo de América, como se conocía a este botánico en los medios científicos europeos-, Humboldt optó por esta segunda alternativa. Navegaron entonces por el Magdalena durante cincuenta y cinco días hasta el pueblo de Honda. Desde allí, con Bonpland de nuevo atacada por las fiebres, los viajeros ascendieron a lomo de mula el flanco oeste de la Cordillera Oriental, utilizando el camino real hasta la fresca altiplanicie bogotana, muy peligroso por lo abrupto del recorrido. La oportunidad de compartir descubrimientos con Mutis y enterarse en detalle de las investigaciones de la Expedición Botánica fue para Humboldt una de sus más gratas experiencias en el Nuevo Mundo. Luego, el 8 de septiembre de 1801, el viaje continuó hacia el sudoeste, en dirección a Quito, descendiendo otra vez al vale del Magdalena, remontando los demás ramales andinos y enlazando los sitios habitados más importantes, como Ibagué, Cartago, Popayán, Pasto, Ibarra y finalmente Quito, a donde los viajeros llegaron el 6 de enero de 1802.

Si bien Venezuela y Nueva Granada habían sido el escenario apropiado para las investigaciones sobre plantas, y Cuba - y después México- el objeto de estudios de geografía humana, los alrededores volcánicos de Quito concentraron la atención de Humboldt en exploración geológica. Más tarde, en Lima, el mar sería un objeto de singular interés, que lo llevaría a descubrir la corriente que todavía se suele identificar con el nombre del Barón. En la sierra ecuatoriana, la escalada de los volcanes Pichincha y Chimborazo, entre otros, dieron a Humboldt el puesto de primer alpinista del mundo durante mucho tiempo.

Fue en Quito, en 1801, donde Humboldt pudo alternar con Francisco José de Caldas, el más notable científico criollo del virreinato de la Nueva Granada, por muchos títulos reconocido como el padre de la geografía colombiana. Caldas había estado ansioso de entablar una relación científica con el geógrafo alemán, e incluso había acariciado la idea de que éste le permitiera incorporarse a sus viajes. Par razones que nunca han sido bien aclaradas, el Barón rehusó a Caldas cualquier género de asociación y ayuda, a pesar de que le reconoció sus méritos. Muy conocida es la apreciación que escribió Humboldt en 1802, en nota citada por Bateman (1978: 71).

Este Mr. Caldas es un prodigio en astronomía. Nacido en las tinieblas de Popayán, ha sabido elevarse, formarse barómetros, octantes, sectores, cuartos de círculo de madera; mide latitudes con gnomones de 15 a 20 pies. ¿Qué habría hecho este genio en medio de un pueblo culto y qué no debíamos esperar de él en un país en que no se necesita hacerlo todo por sí mismos!

(Hasta ahí Humboldt. Y podría aquí caber una especulación parentética: Qué no habría hecho Caldas si Humboldt hubiese tenido en su temperamento algo de mecenas. Y qué no habrían hecho Caldas y muchos otros, tanto en el Nuevo como en el Viejo Mundos, si entre las aficiones del Barón hubiese tenido cabida alguna formal inclinación pedagógica para formar discípulos que continuasen su obra de colosal anticipación). 
Los últimos meses de 1802 y principios de 1803 los pasó Humboldt en el Perú, desde donde se trasladó a Guayaquil y luego a México, a realizar importantes observaciones sobre economía colonial, entre otras. Tras una breve nueva temporada en Cuba, el Barón terminó sus viajes en el Nuevo Mundo con una visita a Estados Unidos. Allí, en mayo de 1804, tuvo la grata experiencia de ser huésped del presidente Thomas Jefferson, también un gran aficionado a los estudios geográficos. Humboldt y Bonpland retornaron a Europa por Burdeos el 30 de junio de 1804.

A partir de 1806, París sería durante varios años el lugar de residencia de Humboldt, ahora dedicado a las dispendiosas tareas de ordenar todos sus materiales científicos y escribir uno tras otro los volúmenes del Voyage aux régions équinoxiales du Nouveau Continent. Ese oficio le llevaría casi 20 años. El esfuerzo resultó en 30 tomos escritas originalmente en francés, el primero de los cuales salió de las prensas de Levrault et Schoell en 1808; el último en 1834.

Alexander von Humboldt volvió a Berlín en 1827, al ser forzado por sus deudas a aceptar una bien remunerada posición en la corte prusiana. Desde entonces, hasta su muerte en 1859, Berlín sería su residencia permanente, excepto por algunos viajes ocasionales al exterior, el más importante de los cuales fue el que realizó por los dominios del zar de Rusia durante algunos meses de 1829. En medio de la fama que lo rodeaba, ese viaje fue una verdadera gira triunfal del sabio, pues en cada aldea que visitaba, los habitantes lo recibían con los vítores que solo están reservados para los grandes héroes militares.

Humboldt pasó los últimos 20 años de su vida trabajando incansable en la capital prusiana. Era increíblemente constante en su tarea de ampliar su legado científico, basado en su propia experiencia y en la de quienes lo precedieron, contribución histórica de orígenes y naturaleza tan diversos de la cual su sorprendente erudición tenía completo dominio. Entre noviembre de 1827 y abril de 1828 Humboldt ejerció transitoriamente como docente excepcional, dictando en la Real Academia de Ciencias de Berlín un ciclo de 61 conferencias, ante entusiastas y atiborradas audiencias. Muchos años más tarde, Jean Louis R. Agassiz (1807-1873) recogería su propia impresión, y la de otros embelesados oyentes, calificando sin vacilar a Humboldt como "profesor" que sabía "combinar su inmenso bagaje de conocimientos con la simplicidad de la expresión, evitando todos los tecnicismos no absolutamente necesarios para la exposición del tema" (Agassiz, 1869: 32, en trad.).

Los temas tratados en aquellas conferencias fueron una formulación anticipada de la que sería su última obra, una especie de suma cosmográfica que para él mismo representaba la culminación y síntesis de todo su esfuerzo científico. Aunque el trabajo formal de su redacción empezaría en 1834, cuando él ya frisaba los 65 años, la idea del Cosmos era el resultado de toda una vida de estudio. En carta de aquel año a Karl Varnhagen, citada por Livingstone (1992: 136, en trad.), esbozaba de la siguiente manera su último proyecto:

Tengo la loca idea de retratar en un solo trabajo todo el universo material, todo lo que conocemos de los fenómenos de cielo y tierra, desde las nebulas de las estrellas hasta los musgos que crecen en las rocas graníticas - y todo eso en estilo vívido que estimule y cautive el sentimiento. Cada idea grande e importante de mi escrito deberá ser consignada allí codo a codo con los hechos. Deberá dibujar una época en el génesis espiritual de la humanidad - en el conocimiento de la naturaleza... Mi título es Cosmos.

En el propio prólogo del Cosmos, Humboldt habría de confesar que el esfuerzo de toda una vida de trabajo científico estuvo subrayado por su compromiso con una meta más alta en mente:

La principal motivación que me orientó fue mi ferviente anhelo de discernir los fenómenos físicos en su conexión general, y representar la Naturaleza como un gran todo, movida y animada por sus propias fuerzas (Humboldt 1997: I: 7, en trad.).

Humboldt cumplió a cabalidad este cometido en su último compromiso con la ciencia y consigo mismo. Para el prologuista de una reciente re-edición del Cosmos, esta obra puede tomarse como la introducción de una nueva e independiente ciencia positiva, la physische Weltbeschreibung, a sea, cosmografía física, en la concepción humboldtiana (Dettelbach 1997). Es la suma de una postura erudita diferente, para la que muchos no le escatimaron el calificativo de "ciencia humboldtiana".

La misma trascendencia y expectativa que rodeó la aparición del Cosmos no excluyó, sin embargo, los comentarios críticas de otros contemporáneos que, en el extrema opuesto de la 
controversia, llegaron a reducirlo a la categoría de tratado de indiscutible mérito literario pero carente de valor científico trascendente. Para el finado profesor de Wisconsin, Richard Hartshome (1899-1992), una de las más respetadas autoridades relacionadas con la historia de la geografía alemana, la gran tesis del Cosmos, que fue de primera importancia para su autor, tiene ahora poco atractivo tanta para la ciencia como para la filosofía. Sus estudios de geografía sistemática, pioneros en el desarrollo histórica del campa, hace ya tiempo se volvieron obsoletos. Otro tanta ocurre en parte con sus trabajos sobre lo que se dio en llamar "geografía regional comparativa" (Hartshorne 1939: 82).

A casi siglo y media de su muerte y doscientos años después del viaje al Nuevo Mundo, reiteramos, la figura de Humboldt, lejos de desteñirse, signe atrayendo el interés de muchas intelectuales que quieren re-examinarla. ¿En qué descansa la perdurabilidad del legado humboldtiano? el tiempo de Humboldt coincidió con la época de la parcelación disciplinaria del conocimiento, la independencia de las ciencias y de las profesiones. No es rara, entonces, que siglas después, en letra de imprenta, en simposios y seminarios, en la web3, se le rebusquen a la abra humboldtiana toda suerte de asociaciones disciplinarias, tanto para exaltar su memoria como para recabar algún grado de parentela científica que contribuya a la legitimación de determinada parcela de la comunidad académica.

Tradicionalmente, sin embargo, han sido los geógrafos quienes reclaman la mayor cuata de derecho de primogenitura en el legado Humboldt. La literatura del pensamiento geográfico es recurrente a este respecto. Veamos unos pocos ejemplos. Hanno Beck, uno de los mejor documentados especialistas actuales sobre el sabio, no vacila en calificarlo como "el mayor geógrafo de la época moderna" (Beck 1986). Por otro lado, reconociéndolo como a "uno de los fundadores convencionales de la geografía moderna", Livingstone acredita el empeño de Humboldt para desarrollar una forma de trabajo científico que hizo pleno uso de las tradiciones geográficas de la Europa del siglo dieciocho, trascendiendo de aquella herencia, sin embargo, un énfasis nuevo sobre la importancia de la exactitud, la sofisticación conceptual y la utilización de la más avanzada instrumentación analítica (Livingstone 1992: 138, en trad.).

Otro crítico lo califica como "otra de las figuras paternas de la corriente principal de la geografía moderna", a tiempo que indica que "la geografía de Humboldt requirió de una comprensión cósmica de las fuerzas modeladoras del entorno ambiental, que integra por igual a las ciencias naturales y sociales - integración que se hizo evidente en el título de su obra monumental, el Cosmos" (Olwig 1996: 80, en trad.). Preston James, por su parte, sostenía que Humboldt "fue, en efecto, un geógrafo, porque se preguntó sobre las interconexiones entre cosas y eventos de origen diverso, haciendo a un lado las nuevas barreras que se erigían entre las disciplinas, para lograr una última mirada majestuosa del cosmos" (James and Martiu 1981: 146 en trad.). Entre el común de los miembros de la comunidad geográfica es poco menos que axiomático reconocer la singular posición de Humboldt en la historia de la geografía de todos los tiempos, como también es casi lugar común que se le acredite a secas como "padre" de la geografía científica, evidentemente una ponderación hecha con mayor unanimidad que la referida a la clásica absoluta paternidad de la disciplina. Como se recordará, algunos asignan a Eratóstenes esta condición, mientras otros la adjudican a Heródoto — can la que los geógrafos emparentarían en alto grado de consanguinidad intelectual con los historiadores, que tienen también a este narrador griego como su padre putativo, lo cual por cierto refleja la estrecha asociación que siempre han mantenido estas dos comunidades eruditas.

Mas hay también quienes no concuerdan del todo con el reconocimiento mayoritario de Humboldt como fundador. Algunos de las geógrafos que le han dedicado tiempo a la historia del pensamiento geográfico no le acreditan - ni a veces tampoco a su contemporáneo Karl Ritter (1779-1859) - el papel de fundador de la geografía moderna. Incluso hay quienes ni siquiera mencionan su nombre. Sin duda, se trata de extremismos en la percepción de la obra del sabio, que pecan de tanta exageración negativa, como lo hacen quienes trazan todas los desarrollos subsiguientes en geografía como genéticamente dependientes de la que él opinó en términos metodológicas o realizó en investigación sustantiva. Hay quienes dejan notar un cierto grado de frustración sobre la real trascendencia del aporte humboldtiano. El geógrafo finlandés Grauö, por ejemplo (1981: 29-30), dice sorprenderse de que, con el ascendiente científico de que sin duda 
disfrutó en Europa, Humboldt no hubiese hecho acceder a la geografía desde principias del siglo diecinueve al status de disciplina científica plenamente reconocida. Para este geógrafo, ese despegue solo se logró al cierre de la centuria, como resultado de nuevas fuerzas orientadas a satisfacer "las metas externas de la sociedad", que dieron como resultado la apertura generalizada de la geografía universitaria, cuyas cuadras docentes originales debieron ser provistos con maestros no entrenados como geógrafos y sin significativos o ningunos enlaces teóricos con Humboldt a Ritter. en su propia época, Julius Frõbel (1805-1893) se atrevió a calificar gran parte de los escritos de Humboldt como una especie de "geografía histórico-filosófica" no científica (Fröbel 1832, cit. por Hartshorne 1939: 82).

Más todavía: A partir de la tesis de que "a pesar de la antigüedad del término geografía, la geografía del siglo veinte tiene poco que ver con la del diecinueve", el profesar Horacio Capel, en un artículo por la demás excelente sobre la institucionalización de la disciplina, es aparentemente más parco en la acreditación. Escribiendo sobre los reconocidos maestros fundadores, concede que aunque Ritter fue un geógrafo, sus intereses disciplinarios eran tan ambiguos que su afiliación bien podría ubicarse "tanto en historia como en geografía"; y agrega que caso bien distinta era el de Humboldt, que "solo con dificultad puede ser considerado geógrafo en el sentido estricto de la palabra" (Capel 1981: 40, en trad.). Para Capel, la circunstancia de que el pensamiento de Humboldt estuvo influido por las ideas dominantes de la filosofía natural, entre ellas la de la unidad de la naturaleza, y el que para explicarla se hubiese adentrado en la observación y estudio de una gran variedad de fenómenos, lo sitúan más como naturalista empírico que como geógrafo. No obstante, más adelante reconoce que en la rica variedad de su trabajo científico pueden verse "los fundamentos de diversas ciencias especializadas, tales como la botánica, la meteorología y la geofísica".

Sí, el Barón fue un naturalista notable, sin duda, y en ello concordamos con las apreciaciones de muchos otros autores sobre el conjunto de los trabajos de Humboldt. pero la verdad es que fue más que eso, astrónomo, por ejemplo, y muchas cosas más, como la de estudioso pragmático que consistentemente trataba de incorporar a sus investigaciones un componente de aplicación o de ayuda para el mejoramiento de sociedades y países. Sin que por ello dejase de lado especulaciones juiciosas que reflejaban una mente de alcances premonitorios. Un comentador reciente de la vida y obra de Humboldt destaca del amplio espectro de su versatilidad intelectual, precisamente, una condición de geógrafo de proyecciones que trascendían las preocupaciones de su tiempo, todavía alejadas de problemas que hay son apremiantes:

Humboldt no fue solamente un naturalista y el creador de la geografía física (entonces conocida como physique du monde), sino que además tiene el mérito de haber estudiado, desde un enfoque que hay nos resulta moderno y ecológico, la relación hombre-naturaleza. Mas no en el sentido de un determinismo de la naturaleza, sino de relaciones recíprocas y de la acción conjunta dentro de una visión sintética. De este modo, en la geografía científica en proceso de formación, se dio un paso decisivo en dirección hacia una "geografía regional" que asignaba una importancia significativa a los factores antropógenos... (Kolihepp 1999: 15).

Aparte de las apreciaciones puramente conceptuales, es importante que intentemos precisar el grado con que Humboldt pueda ser considerado como geógrafo, por formación, por las ideas, principios geagráficos y métodos que manejó, $\mathrm{y}$, sobre todo, por la producción que nos legó en publicaciones. Igualmente, importaría establecer el grado de influencia de la obra de Humboldt sobre los subsiguientes desarrollos filosóficos y metodológicas de la geografía. Dentro del ámbito reservado a un ensayo como el presente, esta tarea debe entenderse como una mera aproximación. Sin que con esta vayamos a excusar las limitaciones del escrito, debe reconocerse que el análisis de la vasta obra humboldtiana, y la evaluación de la de quienes a finales del siglo diecinueve y principios del veinte definieron las bases metodológicas modernas de la disciplina, ciertamente requieren el espacio de un erudito y voluminoso tratado.

¿Fue Humboldt formado sistemáticamente como geógrafo?

No, como ninguno de sus contemporáneos la fue, por la sencilla razón de que las escuelas de geografía apenas aparecerían en las universidades alemanas unas dos décadas después de su muerte. Uno de sus biógrafos dice que "el 26 de febrero [de 1792], celebró con sus condiscípulos el término feliz de sus estudios" en la Escuela de Minas de Freiburg (De Terra 1956: 50). Nada 
dice este autor de qué específicamente se graduó, ni cuál título universitario incorporó a su currículo vitae. Las ciencias y las carreras profesionales derivadas de una formación universitaria apenas estaban tomando forma en esa época, y con la excepción de unos pocos casos, como el de la medicina, los estudios universitarios no hacían mayor énfasis en el especialismo. Por otra parte, el misma carácter de la universidad alemana, que ya empezaba a romper sus ataduras medievales, no confinó la dimensión intelectual del joven Humboldt dentro de una carrera específica, que lo restringiera "por prescripción y rutina", como anotara Agassiz (1869: 7). Por el contrario, le abrió todas las ramas del saber a su ilimitada curiosidad. Ese escenario formativo, sin duda ninguna, habría de contribuir a fomentar el universalismo intelectual, por un lado, mientras por el otro deparaba al estudiante la libre oportunidad de optimizar preferencias hacia intereses científicos particulares. Humboldt mismo se trazó su propio programa de estudios en Frankfurt, Gottingen y Freiburg, cursando las asignaturas que le interesaban (más las que de mala gana tenía que ver para atender los caprichos maternos).

¿De dónde, en más amplios contextos, proviene la ciencia humboldtiana, o como se diría hoy, el proyecto científico-metodológico humboldtiano? Varias influencias intelectuales claves concurrieron en el proceso de la formación académica de Humboldt. A su singular estilo de ver y trabajar la geografía contribuyeran, como bien lo observa Livingstone (1992: 134), el empirismo de Bacon, las ideales filosóficos de una ciencia universal de Kant, la pasión por las bellezas de la naturaleza de Georg Forster y, en gran medida, la búsqueda idealista de Goethe y Schelling por un principio coordinador trascendental. En lo que a la ciencia geográfica concierne, más que la formación universitaria en aulas y laboratorios, la que hicieran del joven Humboldt un geógrafo fueron sus frecuentes viajes de estudio a través de lo que ahora son territorios de Austria, República Checa y Eslovaquia; Polonia, el norte de Italia, Países Bajos, Francia y Bélgica, Inglaterra, los Alpes Suizos y, desde luego, Alemania. Todas esas experiencias moldearon su capacidad de percepción y análisis geográfico, según la opinión de un crítico, porque a través de las mismas aprendió de primera mano acerca de las distribuciones espaciales de la vida orgánica y de sus ataduras umbilicales con el medio ambiente, y esta provocó en él un respeto perdurable por los métodos empíricas. Pero si el procedimiento era empírica e inductivo, desde siempre Humboldt se esforzó por la búsqueda de lo universal detrás de lo particular, por los patrones y regularidades subyacentes y las unidades que integraban la naturaleza en tan hermoso y funcional sistema (Livingstone (1992: 135, en trad.).

Las contribuciones sustantivas a la geografía, empezando por la Geografía de las plantas, y luego en estudios sobre regiones particulares, reflejan un enfoque inductivo genuinamente científico y erudito en el trabajo geográfico de Humboldt, y, sin duda, marcan un claro contraste con lo que antes de él se hacia en geografía. Por otra parte, los medios de que se valió para ese empeño trascendente, tipificaron una ciencia innovadora, cuya caracterización tal vez se pueda resumir así, según el último autor citado:

Estricta medición de los fenómenos (con un instrumental impresionante como el que trajo a América);

La matriz regional resultante de la interacción de la vida orgánica con su entorno, que diversifica la superficie y genera un número grande de regiones naturales; $\mathrm{y}$

El impulso cartográfico, es decir la reconstrucción gráfica de datas distribuidas espacialmente. De sus aportes a esta temática se derivaron los isomapas.

En suma: exactitud, sofisticación conceptual y utilización de lo último en instrumentación analítica (Livingstone 1992: 137-38).

Si bien Humboldt mismo nunca pretendió encasillarse como geógrafo, ni estuvo en su temperamento la idea de crear escuela alguna que continuara su particular manera de hacer geografía, si hay suficientes evidencias en su legado que de sobra la pueden calificar como miembro no declarado de este sector particular de la ciencia. Por lo demás hay que reconocer, como lo observaba el profesor Hartshorne (1939: 65), que para Humboldt la geografía, como campo de estudio, no podía tomarse como un fin en si misma, sino como un media para comprender "la unidad armónica del cosmos", como "un todo viviente", "una unidad en multiplicidad" (posición que probablemente refleja influencias del romanticismo, derivadas a través de Goethe, con quien él tuvo una cercana relación de amistad). La propia concepción que 
Humboldt tenía sobre la unidad de la naturaleza, y su pretensión de comprender y explicar la interacción de los fenómenos, que a la vez le daban variedad y-armonía, dibujan su talante indudablemente universalista. Por eso a Humboldt se le suele considerar como el último de los grandes cosmógrafos.

¿Cómo se proyecta conceptualmente la obra de Humboldt en la ciencia geográfica? La evolución moderna de la teoría geográfica, como un trabajo sistemático y deliberado, tuvo su primera línea principal de desarrollo en los escritos de Hettner, supuestamente a partir de formulaciones metodológicas provenientes de Kant y Humboldt. Las proposiciones pioneras de estos pensadores habrían sido replanteadas por Hettner, en el sentido de que la geografía es una ciencia que se ocupa de las variaciones espaciales, del mismo modo que la historia expresa el desarrollo de los fenómenos en términos temporales. Esta comparación de enfoques - $\mathrm{O}$ metodología - arranca de las relaciones seculares que siempre unieron a la geografía y la historia.

Una característica muy general en la obra de Humboldt, desde el punto de vista de la geografía, es la relativa escasez de pronunciamientos conceptuales y metodológicas sobre la disciplina, de elaboración amplia. Se diría que para él fue más significativa el investigar y describir analíticamente los fenómenos reales que interactúan en la superficie del planeta, y producir una vasta obra sustantiva, que especular sobre cómo hacerlo. Pero de todas maneras sus contribuciones al respecto, tanta aquellas que fueron fruto de su propio discernimiento como las que formuló a partir de los puntos de vista de quienes lo precedieron, marcan una ruptura en el pensamiento y obrar geográficos imposible de ignorar.

La pista de la evolución conceptual moderna de la geografía puede ser seguida en un trabajo de Hartshorne (1958), tomando como partida la introducción que hacia Kant al curso elemental de geografía física que enseñaba en Königsberg desde mediados del siglo XVIII. En este trabajo de Hartshorne, entre otras cosas, se trata de establecer el grado de influencia que pudo haber recibido Humboldt de las concepciones kantianas. Parece quedar claro que después de que Georg Forster lo iniciara en geografía en el propio escenario de trabajo de este campo del conocimiento,, i.e. el mundo real en donde viven y se relacionan personas, organismos y cosas, sin ningún aparente conocimiento de lo sostenido por Kant en sus poco divulgadas conferencias, Humboldt precisó por su cuenta los aspectos teóricos básicos de su concepción de la geografía. Él fue muy claro - algo en lo que todavía muchos no lo son- en distinguir tanto los fenómenos que son objeto de estudio de la geografía como la manera peculiar como ésta los estudia, a diferencia de las demás ciencias. Desde muy temprano en su evolución científica, en el estudio sobre la Florae Fribergensis Specimen, Humboldt (1793) indicó que las ciencias físicas y naturales tienen como objeto ciertos fenómenos terrestres, plantas individuales, animales, objetos sólidos y fósiles, a los cuales les estudian las formas, construcción y procesos, para ordenarlos taxonómicamente de acuerdo con sus analogías internas particulares. La geografía también estudia esos objetos, observó Humboldt, en cuanto coexisten en un área, relacionados entre si. No los estudia separadamente sino como un todo, en conexión espacial. en otras palabras, los enfoques y métodos peculiares como se estudian los fenómenos marcan la individualización de las disciplinas. Tal fue precisamente la diferencia que él identificó entre botánica y geografía de las plantas, fruto de la comparación que sigue teniendo plena validez para distinguir las ramas especializadas de la geografía de las correspondientes ciencias sistemáticas. Y reconocía que a diferencia de las otras ciencias, la geografía lleva además implícita un enfoque genético, histórico, puesto que le conciernen los cambios experimentados por todos los fenómenos en el tiempo. El enfoque espacial humboldtiano, su concepción prístina sobre la naturaleza de la geografía, publicada cuando su autor tenía 24 años, en una nota de pie de página en latín, fue su guía conceptual inalterable, pues la volvería a incluir en el Cosmos. La siguiente es nuestra versión al español de la traducción completa al inglés hecha por Hartshorne (1967: 78-79) de esa especie de declaración de principias geográficos de Humboldt:

La geognosia (Erdkunde) estudia la naturaleza animada e inanimada... tanto los cuerpos orgánicos como los inorgánicos. Se la divide en tres partes: geografía de la roca sólida, que Werner ha estudiado industriosamente; geografía zoológica, cuyas bases han sido echadas por Zimmerman; y la geografía de las plantas, que nuestros colegas han dejado sin tocar. Las 
observaciones de las partes individuales de los árboles a las hierbas de ninguna manera pueden ser consideradas como geografía de las plantas; en vez de aquello, la geografía de las plantas traza las conexiones y relaciones mediante las cuales todas las plantas son ligadas entre sí,, designa en qué tierras se hallan, en qué condiciones atmosféricas viven, y dice de la destrucción de rocas y piedras por aquellas formas primitivas de las más poderosas algas y las raíces de los árboles, y describe la superficie de la tierra en la que el humus es preparado. Es esto lo que distingue a la geografía del estudio de la naturaleza, falsamente llamado historia natural; la zoología (zoognosia), botánica (fitognosia) y la geología (orytognosia); todas ellas forman parte del estudio dela naturaleza, pero ellas estudian únicamente las formas, anatomía, procesos, etc., de animales individuales, plantas, cosas metálicas o fósiles. La historia de la tierra, más cercanamente afiliada con la geografía que con el estudio natural, pero hasta el momento no intentada por nadie, estudia los tipos de plantas y animales que habitaron la tierra primitiva, sus migraciones y la desaparición de la mayoría de ellas, la génesis de las montañas, valles, formaciones rocosas y vetas minerales... la superficie de la tierra gradualmente cubierta de humus y plantas, de nuevo denudada por violentas inundaciones de las corrientes, y una vez más secada y cubierta de hierbas. Así la historia zoológica, la historia de las plantas, y la historia de las rocas, que cuentan solo el estado pasado de la tierra, también deben distinguirse claramente de la geografía.

Glacken (1967: 543) nota que la manera de consignar la filosofía de la naturaleza se consolida muy temprano en el modelo humboldtiano, a partir del Essai sur la Géographie des Plants (Humboldt et Bonpland 1805). De acuerdo con Glacken, la visión hnmboldtiana de la naturaleza es más específica y detallada que otras anteriores, principalmente parque Humboldt había viajado mucho y hecho numerosas observaciones personalmente, y porque la suya era una concepción libre de explicaciones teleológicas4, que tomaba en cuenta por igual las modificaciones de la naturaleza por el hombre y las eventuales influencias que el medio ambiente ejerce sobre aquél.

La concepción de la unidad de la naturaleza subraya todo el pensamiento científico-filosófico humbaldtiano, aunque con mayor énfasis en lo que concierne a la geografía, pero no en el sentid de un simple agregado de cosas en el espacio terrestre, sino en términos de una coherente asociación de elementos interdependientes. Esa axiomática noción de la "unidad" de lo natural incluía - como se ha trascrito antes - tanto lo orgánico como lo inorgánico, lo humano y lo no humano, lo inmaterial y lo material. La exclusión de cualquiera de esas partes no solo seria arbitraria sino que rompería la coherencia y unidad del todo. Sin utilizar la fraseología a la que hay estamos tan acostumbrados, el fundador de la geografía moderna estaba anticipándose a los lineamientos básicos de la teoría sistémica. Por ello la geografía de Humboldt era ciertamente general, opuesta a la idea de quienes pretendían restringirla apenas al natürliche Landschaft, pues todas las presentes condiciones de un área deberían ser estudiadas. Su principio rector era que "en el gran encadenamiento de causas y efectos, ningún material ni actividad puede ser estudiada en aislamiento". La esquematización de la "geografía física" (lo que hoy llamaríamos geografía sistemática o general), como la enunció en el Cosmos, debía culminar con una sección sobre el hombre, la cual contemplaría aspectos tanto espirituales como materiales, e incluiría la consideración de problemas estéticos y morales. Cierto es que en muchos de los trabajos de Humboldt aquellas aspectos "culturales", como los llamaríamos hoy, no aparecen por parte alguna. Ello se debió, según su propia aclaración, a que sus áreas de estudio fueron casi siempre marginales, sin gentes y sin sus obras y efectos culturales. En su Relation historique du Voyage aux régions équinoxiales du Nouveau Continent (3 volúmenes, Paris, 1814-25), Humboldt enfatizó que su pretensión era no solo describir el clima y la apariencia del paisaje, variable de acuerdo con sus suelos y cubierta vegetal, sino también la influencia del clima sobre la vida orgánica, la dirección de montañas y ríos, que separan lo mismo las razas del hombre que las saciedades de plantas, y "las modificaciones que se encuentran en la condición de los pueblos situados en diferentes latitudes y en circunstancias más o menos favorables para el desarrollo de sus facultades".

A Humboldt se deben, según un pensador ya citado, las primeras precisiones sobre el desarrollo de la geografía sistemática, contribución que se encuentra "no solamente en el valor de los trabajos que él mismo produjo, sino también en el hecho de que por primera vez él dibujó con 
nitidez la distinción entre estudios sistemáticos, pero corológicos, en geografía, y estudios sistemáticas en las ciencias especiales" (Hartshorne 1939: 78, en trad.). En sentido práctico, Hnmboldt se percató de la imposibilidad de abarcar en un estudio geográfico todas las interrelaciones posibles, por lo que en sus trabajos concentró su atención sobre ciertas relaciones, e.g. las que existían entre las plantas como un todo (vegetación) y el clima, su principal determinante directo o a través del suelo, con un principio unificador, o sea lo que ahora llamaríamos dimensión espacial.

Dando el crédito apropiada a Bernhard Varen, Varenius (1622-1650), el otro gran precursor alemán, para Humboldt era clara que el estudio geográfico podía ser enfocado de manera regional, o especial, y sistemática. La geografía sistemática —que Varenius identificó como general, y que en el siglo XIX se conoció como "geografía física" (o physische Erdbeschreibung, como solía denominarla Humboldt) - era su opción preferida para el enfoque holista de su discurso científico. "El propósito último de la geografía física — sostenía- es reconocer la unidad en la vasta diversidad de fenómenos, y mediante el ejercicio del pensamiento y la combinación de observaciones, discernir la constancia de los fenómenos en medio de cambios aparentes" (Cosmos 1997 [1858]: I, 61, en trad.). No sobra reiterar que donde Humboldt aplicó con más claridad el enfoque sistemático, general, fue en el trabajo sobre geografía de las plantas (Humboldt et Bonpland 1805), al cual se le considera antecedente directo de la fitogeografía moderna. Incidentalmente, también hay que reconocer que su tratamiento de los componentes atmosféricos, que explican la variable distribución de los suelos y la vegetación, fue tan sofisticada que justifica su paternidad disciplinaria para la climatología (Castrillón Aldana 2000).

Como científico que sabia hacia donde ir, Humboldt insistió en lo importante que era para los geógrafos mantener la mente puesta en la generalización de las relaciones mutuas de los fenómenos. La siguiente cita al respecto, tomada de la Relation historique [tomada aquí de la versión al español de Lisandro Alvarado] es bien conocida:

El gran problema de la física del mundo [la physique du monde, physische Erdbeschreibun, o geografía física] es determinar la forma de esos tipos [de seres en relación unos con otros], las leyes de esas relaciones, los lazos eternos que encadenan los fenómenos de la vida y los de la naturaleza inanimada (Humboldt 1956, 1: 6).

Sin embargo, él no desligó nunca la geografía sistemática de la regional, ni rehuyó en modo alguno su práctica, como se mostrará más adelante. Para Humboldt los estudios regionales eran la materia prima de la generalización, es decir de la geografía sistemática. en la introducción a la Relation historique, ya citada, indicaba su propósito de hacer conocer los países visitados "y recoger hechos que diesen luz sobre una ciencia apenas bosquejada y asaz vagamente designada con los nombres de Física del mundo, de Teoría de la tierra, o de Geografía Física" (Humboldt 1956:1: 4). Y en el Cosmos se reafirma esa relación disciplinaria, cuando declara que "la descripción de diferentes países ciertamente nos proporciona los materiales más importantes para la composición de la geografía física". En ampliación de este punto de vista, no resistimos la tentación de transcribir textualmente lo siguiente, traducido de la versión inglesa de 1858 del Cosmos, hecha por Elise C. Otté:

Es sometiendo las observaciones aisladas al proceso del pensamiento, combinándolas y comparándolas, como podemos descubrir las relaciones que existen en común entre la distribución climática de los seres y la individualidad de las formas orgánicas (en la morfología o historia natural descriptiva de plantas y animales); y es a través de la inducción como llegamos a comprender leyes numéricas...

Y concluía Humboldt:

Consideraciones de esta naturaleza, por su tendencia a la generalización, imprimen un carácter más noble a la descripción física del globo, y nos habilitan para entender de qué manera el aspecto del escenario, a sea, la impresión producida en la mente por la fisonomía de la vegetación, depende de la distribución local, el número y la exhuberancia del crecimiento de las formas vegetales que predominan sobre el conjunto general (Humboldt 1997 [1858] I: 60-61).

Quizás faltan ensayos sobre el grada de validez con que la contribución humboldtiana pueda adoptarse como antecedente válido de la geografía humana. Es clara que Humboldt no intentó ninguna separación sistemática entre la geografía de los fenómenos naturales y la del hombre y 
sus obras. Lo cierto es que hasta entonces nadie lo había intentado, quedando tal demarcación especializada para cuando a finales del siglo diecinueve otros geógrafos alemanes la formularan.5 No obstante, recurrentemente en el pensamiento del sabio aflora su preocupación par las sociedades humanas, especialmente dentro de un contexto reivindicatorio por cualquier género de discriminación o de injusticia. Diríase que en sus actitudes liberales se esbozaba un toque de alerta orientado a que el geógrafo fuese consciente de su entorno social, que eventualmente obtendría respuesta positiva en las actitudes de muchos, como ocurrió, por ejemplo, en la sensibilidad con la que Carl O. Sauer se acercaba a los problemas de los pobladores de sus regiones de estudio (Leighly 1967). O, extremando hipotéticas concatenaciones, quizás podríamos aventurar alguna parentela de su modo de pensar sobre las miserias de la humanidad con los reclamos de las "geografías comprometidas" de los años 60 y 70 del siglo XX. Las ideas de Humboldt sobre la unidad de la humanidad excluían, por supuesto, cualquier forma de superioridad de razas o regiones. Wolf Lepenies, en una conferencia de bicentenario, anotaba al respecto lo siguiente:

Podríamos describir los limites del pensamiento no eurocéntrico de Alexander von Humboldt exaltando su liberalismo en la esfera social. Nunca dejó de prestar atención al contexto específico en el que habitan los seres humanos y a la historia peculiar que moldea sus tradiciones y pensamientos. Había, sin embargo, una actividad humana donde súbitamente el contexto dejó de importar, o que por la menos no importaba lo suficiente. en principio, la ciencia y la tecnología podrían ser operadas en cualquier parte del mundo y por cualquiera. El oeste no era su propietario (Lepenies 1999, en trad.).

Muchos de los estudiosos humboldtianos destacan como los más geográficos, para el gusto contemporáneo, los trabajos relacionados con la Nueva España (Humboldt 1808-1811, 1978) y la isla de Cuba (Humboldt 1826, 1998). La verdad es que fueron obras maestras de geografía regional con énfasis sociocultural, fruto del enfoque empírico de Humboldt y de su empeño por lograr una cabal comprensión "del carácter natural de las diferentes regiones del mundo", a través de lo cual se pueden establecer claramente las relaciones de éste con el hombre y su cultura. en esos trabajos, en contexto microgeográfico, se examinan las influencias de las fuerzas naturales sobre el hombre, con un cierto dejo de determinismo, aunque se da juego a los factores de la herencia cultural en la explicación de la fisonomía particular de las regiones. Para el propio Humboldt, sin embargo, ese tipo de trabajo - al que definía como economía política - contaba menos que el dedicado a la geografía general. Y es paradójico que mientras sus contribuciones con este enfoque ya quedaron rezagadas y solo se valoran como antecedente histórico de desarrollos posteriores por otros autores, aquellas de la geografía regional se mantienen incólumes, pues son "magistrales descripciones explicativas, analíticas y sintéticas en forma... que permanecen en geografía con valor imperecedero", como sostiene un crítico bien autorizado (Hartshorne 1939: 82, en trad.). Similares opiniones fueron también expresadas antes por Peschel (1877), Hettner (1927), y Plewe (1932). Para Oscar Peschel (1826-1875), uno de los grandes méritos de Humboldt fue su enfoque renovado, analítico, de la geografía regional, o Länderbeschreigung, puesto que en sus trabajos de casos no se limitó a dibujar descriptivamente el área de estudio, sino a "darle vida a través del juego de fuerzas" (Peschel 1877, cit. por Hartshorne 1939: 80, en trad.). Peschel, uno de los primeros historiadores de la geografía, juzgaba que la geografía alcanzó estatura científica a partir de los celebrados ensayos regionales humboldtianos sobre la Nueva España (México) y Cuba. Y concluía que a partir de tales estudios "los geógrafos ya no se preocupan solo por el estudio de las interrelaciones de fenómenos físicos, sino también por los fenómenos históricos o humanos en escena".

En la obra de Humboldt merece análisis más amplio su contribución significativa al recurrente tema de las relaciones del hombre con su medio circundante. Esta cuestión fue puesta en contexto histórico general por Glacken (1967) en su magistral estudio de las relaciones de "naturaleza y cultura en el pensamiento occidental desde los tiempos antiguos hasta fines del siglo XVIII", aunque tal limite fue transgredido precisamente para incluir a Humboldt. Glacken destaca el antecedente de las opiniones de Kant, Goethe y Herder, quienes rechazaron la visión teleológica del mundo - más o menos dominante hasta el siglo de la Ilustración - que consideraba que la naturaleza había sido "diseñada" por el Creador para servir al hombre, su amo y señor. En su 
Ideen zur Philosophie der Geschichte der Menschheit (1784-91), Herder sintetizó todo el pensamiento anterior, alrededor de la discusión de dos problemas: las relaciones de la Humanidad, como un todo, con la Tierra en general; y la reilación de pueblos individuales con sus entornos particulares. Herder, en síntesis, reconoció que el hombre era sujeto de influencias ambientales, pero que a la vez como ser cultural podía transformar y adaptar la naturaleza a sus necesidades, debiendo actuar prudentemente al alterar esta interdependencia.

Por su parte, Humboldt, también apartado de cualquier determinismo teieológico, tomó en cuenta tanto las modificaciones de la naturaleza por los grupos humanos, como las influencias ambientales que éstos debían soportar. Una vez más, sus puntos de vista al respecto aparecen especialmente en el Essai sur la Géographie des plantes (Humboldt et Bonpland 1805). en esa obra, como ya hemos anotado, Humboldt se interesa singularmente en las múltiples relaciones que deben afrontar los seres vivientes, las plantas entre ellos con mayor grada de dependencia, no solo con los elementos físicos de la naturaleza, sino con las saciedades humanas. Muestra Humboldt ejemplos de influencias positivas de la acción cultural, e incluso especula sobre los orígenes de la agricultura, como fruto de las interacciones de sociedades primitivas con su entorno, las cuales conducen a la domesticación como alternativa favorable de subsistencia a la caza a la pesca riesgosas. El tema de las limitaciones o la favorabilidad del medio es examinada con cierto grado de detalle. $\mathrm{Y}$ en otro ensayo complementario, Tableau physique des régions equatoriales, Humboldt (1805: 139-140) muestra simpatía por la milenaria teoría ambientalista del "estímulo de los entornos difíciles", que expresa una relación inversa entre el mayor desarrollo civilizador con las menores condiciones favorables del medio. La supuesta fertilidad exuberante del trópico húmedo no atrajo, según Humboldt, el asentamiento del indígena serrano, que prefirió los climas gélidos y los suelos malos de las altos Andes para desarrollar sus más avanzados grados de civilización. "Humboldt creía — escribe Glacken - que ellos [los indios] permanecen en sus inhóspitas tierras por el amor al terruño y la fuerza de la costumbre... Esta es una observación casual y esquemática, pero hace pensar en una geografía humana que no puede ser explicada solo por el entorno, que incluye las costumbres y la inercia cultural, y que puede sacar ventaja de la comparación de entornos ambientales" (Glacken 1967: 547, en trad.).

No hay muestras amplias de la dedicación de Humboldt al tema político asociado con la estructura espacial de los estados, o a las interacciones entre éstas en términos de competencia territorial, que permitan discernir su clara relación de tipo conceptual o metodológica con una geografía política en ciernes. Como se sabe, estos temas solo empezaron a atraer la atención sistemática de los geógrafos a finales del siglo XIX, especialmente con el trabajo de Ratzel (1897), si bien se reconocen antecedentes que se remontan hasta Estrabón (cf., por ejemplo, a Hartshorne [1935], quien, sin embargo, no alude para nada a Humboldt en este respecto). el tema del aporte geopolítico de Humboldt sigue, pues, abierto a discusión. No obstante, unos cuantos indicios dispersos en su obra y en su biografía nos permiten afirmar, sin duda ninguna, que estas cuestiones no escaparon a su inteligente consideración, a pesar de que su vinculación con la corte prusiana debió coartar sensiblemente su discusión abierta de temas espinosos como los de litigios por limites, alianzas entre potencias imperiales, colonización y emancipación de pueblos y países. Pero bien sabida es la simpatía que Humboldt tuvo por este último derecho geopolítico, lo mismo que el entusiasmo con el que siempre registró la creación republicana de los Estados Unidos de América. Por la obra de Bolívar, a quien al principio creyó un soñador más, Humboldt expresó su admiración epistolar, al tiempo que consignaba su esperanza por los grandes designios que esperaban a los países del norte y sur de la América recién emancipada. El nombre de Humboldt siempre estará asociado con los más grandes ideales del americanismo (Zúñiga 1975), que él de muchas maneras ayudó a inspirar y propugnar.

Como una especie de subproducto de su filosofía de la naturaleza, Humboldt desarrolló un don que llevó al grado de excelencia: su apasionamiento por la descripción. Su entusiasmo se desborda cuando examina "la poesía de la naturaleza", notando cómo en distintos contextos históricos y culturales hay suficientes motivos de inspiración en el proceso de describir las maravillas del entorno. Para él una buena descripción del paisaje, enriquecida por la imaginación de quien lo relata, es un goce comparable al de la percepción sensorial. Hay gran sentido escribió- en. la expresión figurada de los árabes: La mejor descripción es la que convierte en 
ojos los oídos. Insistía en que "pueden darse a las descripciones de la naturaleza contornos fijos y toda el rigor de la ciencia, sin despojarlas del soplo vivificador de la imaginación".

Por supuesto, Humboldt mismo fue un maestro del género, y su vacación romántica quedó inscrita en numerosas instancias de su vena de naturalista-poeta.

Concomitante con lo anterior, Humboldt demostró gran interés en la elegancia del relato geográfico, tanto por el valor intrínseco del tema como por la validez de la aplicación en ciencia, lo cual ilustró con su extraordinaria erudición, mediante ejemplos registrados en épocas y autores pretéritos. Humboldt insistía en que lo científico no debía divorciarse de lo estético. No era simple cuestión de utilizar "frases poéticas". Al respecto apuntaba que las descripciones de la naturaleza pueden ser delimitadas con nitidez y ser científicamente exactas, sin que por ello pierdan el aliento vivo del poder de la imaginación. El aspecto estético debe proceder del presentimiento de interrelación de lo sensual con lo intelectual, del seutimiento de la universalidad, limitación recíproca y unidad de la naturaleza-vida. Y agregaba que el placer intelectual proviene no de la descripción de la percepción sensorial, sino más bien del entendimiento o comprensión del armónico intercambio de las fuerzas en el paisaje.

Una sustancial parte de la obra de Humboldt fue dedicada a debatir las influencias que el paisaje natural tiene sobre la imaginación y la sensibilidad artística. él veía en sus trabajos como observa Giacken (1967: 546) - , en el paisaje multivariado de la naturaleza, "un campo común compartido por la geografía y la estética". Los estudios sobre este particular, agrega Giacken, infortunadamente no fueron continuados, como habría sido deseable, después de la muerte de Humboldt. El mismo analista nota que sólo ha sido desde la creación de tanta fealdad en el paisaje, a partir de la segunda mitad del siglo XIX, que uno se percata de la gran pérdida que esta representa para una disciplina como la geografía, que carece de una fuerte cimentación en estética e historia del arte (Giacken 1967: 546).

¿Cómo era el Humboldt geógrafo, si es que podemos desglosar esta condición desde el ámbito tan variado de su personalidad intelectual y científica? Sus biógrafos (e.g. De Terra 1956; Scnrla 1982) nos lo retratan como uno de los más incansables, acuciosos y rigurosos investigadores de todos los tiempos. Tanto, que unos veinte días antes de su muerte, plenamente lúcido, todavía seguía revisando con el máximo cuidado el texto, notas y referencias de su último despacho para el editor del Cosmos (De Terra 1956: 283).

La estampa con la que se suele asociar a Humboldt es la de un geógrafo de campo, metido en exploraciones científicas casi épicas, lejos del gabinete. Algo, en fin, poco cercano a la idealización enclaustrada con que Vermeer enriqueció la iconografía de los sabios de las coordenadas, de los globos y los mapas. Sin duda, los trabajos de Humboldt en la América tropical y Asia Central, precedidas por sus expediciones en la propia Europa, fueron memorables. Mas lo cierto es que, como la observaba Hartshorne (1939: 50), el tiempo total de trabajo de campo no ocupa más de cinco de los más de 60 años que él dedicó al estudio geográfico y naturalista. Fue en su oficina de Paris y luego en su biblioteca-estudio de Berlín en donde, sacándole todo el bulto posible a una vida social de obligante actividad y a las funciones cortesanas que no podía rehuir, Humboldt se dedicó por igual a construir diariamente su bagaje erudito con cuanta lectura atraía su atención, y a escribir. A escribir toda su enorme producción científica y a mantener una vasta correspondencia, pues se calcula que más de 35.000 cartas salieran de su pluma (Minguet 1989: ix).

Un científico tan exigente como él, consigo mismo y con los demás, podría haber proyectado la imagen de un cultor de la impavidez racionalista en la observación de los fenómenos y aridez objetiva en el discurso académico. Lejos de eso, para Humboldt la contemplación del mundo y de sus múltiples fenómenos era una experiencia de "diferentes grados de gozo", en que "la mente es penetrada por el mismo sentido de la grandiosidad y la vasta expansión de la naturaleza, revelándole al alma, por una inspiración misteriosa, la existencia de las leyes que regulan las fuerzas del universo" (Humboldt 1967, I: 25, en trad.). De esa emotiva comunión con las fuerzas naturales expuestas en los paisajes, cuya suma da la medida del esplendor del universo, derivó Humboldt el estilo que inconfundiblemente adorna muchos de sus escritos. A partir de la observación se debía llegar a "las gráficas delineaciones de la naturaleza, organizadas de acuerdo con el enfoque sistemático, no solo hechas para dar placer a la imaginación, sino que también 
puedan, cuando se consideran apropiadamente, indicar los grados de las impresiones" (Humboldt 1967, I: 27-28, en trad.). No se puede poner mejor esta especie de unidad de lo estético con lo racionalista a como lo hace un exigente crítico de nuestros días:

...constantemente Humboldt orientaba su búsqueda por lo universal detrás de la particular, por los patrones subyacentes y por las unidades que integran la naturaleza en tan operante y hermoso sistema. Es por eso por lo que es digno de destacarse que en los últimas años de su vida, el primer tópico que abordó para discusión en su celebrado Cosmos no fuese ni el método científico ni Los descubrimientos empíricos, sino el gozo de la naturaleza! (Livingstone 1992: 135, en trad.).

Los tiempos cambian y también se transforman, por supuesto, los patrones de comunicación que utilizan los geógrafos; pero tal vez tengamos que lamentar que del vasto cúmulo de procederes que Humboldt legó a la posteridad, muy poco de su estilo se haya perpetuado. Más allá de la incontestable calidad literaria de sus escritos, sin embargo, hay que destacar la incorporación de nuevas terminologías y maneras más avanzadas de presentación de datos en el lenguaje científico de la geografía. De hecho, los mapas y demás ilustraciones humboldtianas son modelos de acabado y belleza. Los geógrafos siempre estarán en deuda con Humboldt, entre tantas cosas en su crédito, por la invención de las isolíneas y los perfiles geográficos, entre los cuales siempre se cita el relacionado con la zonificación vertical de los climas y la biota de las montañas tropicales.

Otro aporte perdurabie de la iniciativa de Humboldt, derivada sin duda de su singular don de gentes - no en balde se desenvolvía como pez en el agua en los más encumbrados círculos sociales e intelectuales y políticas de Paris y Berlín- y de su capacidad de liderazgo, está relacionada con la creación de organizaciones destinadas a la promoción de la actividad geográfica. Concretamente, a su entusiasmo y habilidad de persuasión se deben la fundación en 1821 de la Société de Géographie de Paris, la primera en su género en el mundo, y de la Gessellschaft für Erdkunde de Berlín, en 1828. La iniciativa de reunir a pensadores afines - que años después, a la finalización de su siglo, concretaron otros en el primer cougreso internacional de geógrafos (1871) - la intentó Humboldt en Berlíu tras de su definitivo regreso de Paris, mediante la convocatoria de un congreso científico - el primera de que se tenga noticia - al que a la postre solo concurrieron físicos y matemáticos (Claval 1974: 32).

Humboldt no dejó discípulos directos suyos que de inmediato hubiesen podido consolidar su pensamiento en una escuela geográfica que condujera la disciplina hacia su desarrollo teórico pleno. En sentido estrictamente docente, él no fue maestro de nadie, como tampoco lo fue Caldas, el neogranadino. No que careciese de habilidades pedagógicas ni carisma de comunicador, como bien lo demostrara en su famoso ciclo de conferencias antecesoras del Cosmos, en Berlín, en 1827-28. Uno de sus ilustres oyentes recordaría años después que "como profesor [Humboldt] combinó su inmenso bagaje de conocimientos con la simplicidad de la expresión, evitando todos los tecnicismos no absolutamente necesarias para la exposición del tema" (Agassiz 1869: 32, en trad.). Si bien la docencia sistemática nunca atrajo el interés del sabio, informalmente siempre interactuó solícita con los interesados en el aprendizaje científico. Así lo acredita el ya citado contemporáneo que recibiera tan privilegiada asistencia:

$\mathrm{Su}$ simpatía por todos los jóvenes estudiantes de la naturaleza fue uno de los más nobles rasgos de su larga vida. En verdad puede decirse que, hacia el final de su carrera, era difícil encontrar a un prominente científico, o a un aspirante a serlo, que no estuviera en deuda con él (Agassiz 1869: 44).

En apoyo de la anterior, también se puede citar el caso del médico Franz J.F. Meyen, incorporado como profesor de botánica de la Universidad de Berlín por recomendación de Humboldt. Entre 1830 y 1832, Meyen siguió los pasos de su mentor en el Nuevo Mundo en plan de investigaciones fitogeográficas, las cuales cristalizaron en un libro sobre los esquemas de la geografía de las plantas, en el que la metodología humboldtiana es notablemente sistematizada y perfeccionada a través de análisis sofisticados en los que el fenómeno vegetación es correlacionado espacialmente con otros factores como temperatura y humedad (Nicolson 1995: xxxii).

Esta continuidad inmediata del trabajo humboldtiano no trascendió en mayor grado, como en gran medida ocurriera también con la obra de Ritter, y el desenvolvimiento de la geografía 
moderna perdió ímpetu durante unos pocos años después de la muerte de los dos grandes, en 1859.

Pero eventualmente, la disciplina retomó su ritmo de desarrollo a partir de Los años 70 del siglo diecinueve, esta vez gracias a la apertura generalizada de cátedras de geografía en las universidades europeas. La herencia de Humboldt y de Ritter fue ahora asumida por hombres como Oscar Peschel (1826-1875), Ferdinand von Richthofen (1833-1905) y Friedrich Ratzel (1844-1904), todos ellos del mismo origen alemán que tuvieran los responsables de la ruptura paradigmática de la primera mitad del siglo, y quienes los precedieron en el cultivo de la ciencia de Heródoto y Eratóstenes, como Bernhard Varen (1622-1650), a quien más conocemos como Varenius, Anton Friedrich Büsching (1724-1793) y Emmanuel Kant (1724-1804). La geografía científica es, pues, un desarrollo fundamentalmente alemán. Richthofen empezó a pensar y escribir sistemáticamente sobre filosofía y metodología geográfica, construyendo sobre lo que hizo Humboldt y aportando, por supuesto, sus propias ideas (Richthofen 1883, cit. por Hartshorne, 1939), al tiempo que Peschel y Ratzel sistematizaban la geografía física y la humana (Anthropogeographie), respectivamente. Luego entraría a formar parte de tan selectas huestes Alfred Hettner (1859-1941), otro alemán, por supuesto, primer científico en recibir un doctorado en geografía (Estrasburgo) al cierre del siglo. Él fue el gran metodólogo y sin duda una de las figuras más influyentes de los tiempos modernas en la disciplina geográfica. Richard Hartshorne (1899-1992), de manera paciente y erudita, documentó toda la relación de continuidad de la geografía científica desde Kant a través Humboldt hasta Hettner, principalmente en términos del desarrollo y evolución del concepto corológico como principio rector del pensamiento geográfico post-humboldtiana (Hartshorne 1939, 1967). Sin duda, la investigación documental de Hartshorne ha servido para poner en perspectiva apropiada la figura de Humboldt y lo reivindica como el pionero de la aplicación de la metodología científica en el trabaja geográfico.

Esto, y muchísimo más, fue Humboldt como geógrafo, nuestro mentor ante la historia. Su incuestionable grandeza ha tutelado la comunidad geográfica en el discurrir más o menos proceloso por el muy competitivo mundo científico y académico, en el esfuerzo sostenido por construir un nicho propio y respetable. Nos parece que todas los actos conmemorativos del Bicentenario de principios del siglo XXI siempre servirán, no tanto para mantener vigente la memoria del sabio, que por cuenta propia será eterna entre los humanos, como para repasar con fruición el estímulo intelectual que siempre encontraremos en su obra. En todo tiempo habrá mucho que aprender de las figuras de nuestro pasado disciplinario, y ello hace parte, sin duda, de la formación de un verdadero geógrafo. Es una manera de ampliar horizontes y establecer puntos de referencia para emular. Pero, como muy bien nos lo sermoneaba Sauer, "tal tipo de conducta intelectual significa, sin embargo, aprender a conocer aquellas figuras mediante la revisión directa del conjunto de su trabajo, y no a través de las lecturas criticas de otros" (Sauer 1967 [1941]: 355, en trad.). Y en el caso particular del estudio de Humboldt y de su obra, pueden creernos, esa será una muy grata y estimulante manera de encuentro con las auténticas raíces intelectuales que definen nuestra matrícula como geógrafos, por formación, a por afición.

A nadie, que se sepa, pretendió imponer Humboldt de manera deliberada su manera de pensar la ciencia y de practicarla. pero los geógrafos después de él lo imitaron, perfeccionaron métodos y técnicas de investigación y construyeron teoría a partir de ideas decantadas de su vasta inspiración científica. La geografía ya nunca sería la misma. Doscientos años después de su memorable viaje al Nuevo Mundo los geógrafos miramos con respeto el legado humboldtiano, que cada día se perfila más en dimensión cosmopolita colocándose por encima de todas las escuelas geográficas nacionales y que, sin desmedro de sus medulares contribuciones en el campo, traspone también los linderos de muchas especialidades científicas. Creemos, por lo que hemos documentado y argüido en estas notas, que el gran Humboldt puede seguir inspirando nuestro más o menos aguzado instinto de investigación y que los geógrafos tenemos todo el legítimo derecho - y deber- de mantenerlo como el más destacado de todos los que moran en el panteón del ancestro disciplinario.

Querríamos concluir nuestro tributo a un nuevo centenario humboldtiano con el reconocimiento, proporcionalmente concordante con las mejores expectativas que Humboldt pudo haber acariciado al final de su laboriosa carrera, para su legado como filósofo de la 
naturaleza, como geógrafo, como hombre de ciencia. Difícil dilucidación ésta, por no decir imposible. Pero nos parece que podríamos adivinar algo de tan entrañables esperanzas en lo que intuía uno de sus auto-proclamados discípulos contemporáneos, y tomar prestadas las palabras con las que hace 132 años él cerrara su panegírico conmemorativo del nacimiento del sabio (Agazzis 1869: 57-58):

Todos nasotros tenemos una gran tarea que cumplir. Hasta donde nuestra aliento alcance, el esfuerzo habrá de orientarse a levantar el nivel cultural de nuestras gentes, como Humboldt ha elevado el del mundo. Ojalá que la comunidad general sienta con igual entusiasmo la importancia de cada uno de los pasos que ahora se den para expandir en toda dirección los medios de la más alta cultura... Con la esperanza de esta renovada edad dorada, cerremos filas en regocijo para que el nombre de Humboldt se mantenga por siempre conectado con la educación y el saber... y con las esperanzas e instituciones por las que él sintiera tan profunda y afectiva simpatía.

Que así sea.

Notas

La Fundación Alexander von Humboldt cerró en 1923 por descapitalización, para renacer dos años después bajo la égida de la cancillería alemana, patrocinio que se prolongó hasta 1945. En la posguerra, la presión de ex becarios dela Fundación llevó al jefe del gobierno alemán Konrad Adenauer a reabrirla, en 1953, bajo la dirección inicial del Nóbel Werner Heisenberg. Hoy sigue muy activa, otorgando una de las más famosas becas del mundo a científicos no mayores de 40 años, que ostenten el titulo de Ph.D en cualquier especialidad de las ciencias naturales.

Ideológicamente hablando, Humboldt fue a veces acusado de jacobino y de demagogo materialista. Pero a decir verdad. lejos estuvo él de involucrarse como "revolucionario", o cosa por el estilo. Él si fue un liberal, en el sentido idealista de su muy sensible simpatía y convicción con la causa de la emancipación económica, política e intelectual del individuo. Esta, en esencia, era una postura filosófica derivada de las ideas de la Ilustración dieciochesca, más que un compromiso con un curso de activismo particular, excluyente, por lo demás, de cualquier forma de violencia.

El sitio http://www.hkw.de/english/culture/1999/humboldt/humboldt.html, por ejemplo, presenta un excelente surtido de páginas electrónicas con información variada e interesante sobre la vida, obra, y trascendencia de Humboldt y programas conmemorativos cumplidos tanto en su patria nativa como en otros países.

Humboldt rehuyó en sus obras el enfoque teleológico como explicación de los fenómenos naturales. Como anota Dettelbach (1997: xiii), Humboldt trató por todos los medios de marginar al Cosmos de cualquier controversia político-religiosa. A pesar de algunas menciones a "la creación", él sostenía que el orden de la naturaleza - "el plan de la creación" - puede ser entendido científicamente sin confiar en la fe religiosa o el sentimiento, o sin acudir a la teología natural. Enfatizaba así el carácter secular de la ciencia, afirmando a la vez que la creencia en Dios nada tenía que temer de la ciencia natural. Equilibrismos de este tipo no le evitaron a Humboldt críticas acerbas desde los extremos. Unos lo tildaron de volteriano librepensador, equiparándolo con los hegelianos heterodoxos; los opuestos le criticaban el que hubiese colocado al Cosmos en una suerte de neutralismo, reclamándole que en el contexto intelectual era necesario tomar partido y que el trabajo científico no podía rehuir una postura política.

La primera demarcación especializada de la geografía sistemática fue emprendida por Oscar Peschel y Friedrich Ratzel, a quienes se acredita, respectivamente, la fundación de la geografía física y la geografía humana. El tratado de geografía física del primero fue una publicación póstuma (Peschel 1879); la obra cumbre de Ratzel se publicó en dos volúmenes (Ratzel 1882, 1891).

\footnotetext{
Abstract:Alexander von Humboldt's contributions to the development of modern geography are generally ackoowledged by historians of science, though not always stated precisely out of his many-sided scholarly production. On the occasion of the Bicentennial of his voyage to tropical America, Humboldt's role in setting forth the foundation of an analytical methodology for geography as well as for his monumental substantive work, along with his pervasive and inspiring perrnanence in the geographical tradition, must be recognized as ample justification tu his title as founding father of scientific geography.

Key words: Humboldt, history of geography, modern geography, geagraphical methodology, scientific exploration.

Resumen: Por lo general, los historiadores de la ciencia reconocen la importaocia de Alexander von Humboldt en el desarrollo de la geografía moderna, si bien tal contribución especializada no es claramente desglosada de su multifacética producción científica. Con ocasión del bicentenario de su viaje a la América tropical, el papel de Humboldt en la formulación de las bases de una metodología analítica para la investigación geográfica, y su monumental trabajo sustantivo, lo mismo que su penetrante permanencia e inspiración en la tradición geográfica, deben acreditarse como justificación amplia y suficiente para su título de padre fundador de la geografía científica.
}

Epígrafes: Humboldt, historia de la geografía, geografía moderna, metodología geográfica, exploración científica. 


\section{REFERENCIAS}

AGASSIZ, Louis. 1869. Address delivered au the centennial anniversary of the birth of Alexander von Humboldt. Boston, Boston Society of Natural History.

BATEMAN, Alfredo. 1978. Francisco José de Caldas, el hombre y el sabio. Cali, Biblioteca del Banco Popular.

BECK, Hanno. 1986. Alexander von Humboldt als größter Geograph der Neuzeit. En: Die Dioskuren. Probleme in Leben und Werk der Brüder Humboldt, ed. H. Kessler, Manheim.

CAPEL, Horacio. 1981. Institutionalization of geography and strategies af change. En: Geography, ideology and social concern, ed. D.R. Stoddart (Totowa, NJ, Barnes \& Noble), 37-69.

CASTRILLÓN, Aldana Alberto. 2000. Alejaudro de Humboldt, del catálogo al paisaje. Medellín, Editorial Universidad de Antioquia.

CLAVAL, Paul. 1974. Evolución de la geografia humana. Barcelona, Oikos-Tau.

DETTELBACH, Michael. 1997. Introduction to the 1997 [Cosmos] edition. En: Cosmos- A sketch of the physical description of the Universe, vol. 2, by Alexander von Humboldt, trans. by E.C. Otté (Baltimore and London, The Johns Hopkins University Press), vii-xlvii. [cf. Humboldt, 1997, infra]

DE TERRA, Helmut. 1956. Humboldt: Su vida y su época. México, Editorial Grijalbo (trad. por E. Ugarte, de la versión original inglesa, Humboldt-The life and times of Alexander von Humboldt, New York, Alfred A. Knopf, 1955).

FRÖBEL, Julius. 1832. Ueber die Unterscheidung einer Erdkunde als eigentlicher Naturwissenschaft und einer historischen Erdkunde. Annalen der Erd-, Völkerund Staatenkunde (Berghaus Annalen), 6, 1-10.

GLACKEN, Clarence J. 1967. Traces on the Rhodian Shore: Nature and culture in Western thought from ancient times to the end of the Eighteenth Century. Berkeley, University of California Press.

GRANÖ, Olavi. 1981. External iufluence and internal change in the development of geography. En: Geography, ideology and social concern, ed. D. R. Stoddart (Totowa, NJ, Barnes \& Noble), 17-36.

HAMPE Martínez, Teodoro. 1999. Treinta años de bibliografia humboldtiana en lengua española (1969-1999). Diálogo Científico [Tübingen], 8 (2), 36-56.

HARTSHORNE, Richard. 1935. Recent developments in political geography, I-II. The American Political Science Review, 29 (5-6), 785-804, 943-966.

HARTSHORNE, Richard. 1939. The Nature of Geography: A criticai survey of current thought in the light of the past Lancaster, Pennsylvania, The Association of American Geographers. [Originaimente publicada en Annals of The Association of American Geographers, 29 (3-4), 1939; las citas en el presente trabajo se refieren a la 5a. reimpresión, con correcciones, 1976].

HARTSHORNE, Richard. 1959. Perspective on The Nature of Geography. Chicago, Rand McNally \& Co. for The Association of American Geographers.

HARTSHORNE, Richard. 1967. The concept of geography as a science of space, from Kant and Humboldt to Hettner. en: Introduction to geography: Selected readings, eds. F. E. Dohrs and L. M. Sommers (New York, Thomas Y. Crowell), 74-90. [Originalmente publicado en Annals AAG, 40: 97-108, 1958].

HERMANNS, Ute. 1999. Simposio... "Alexander von Humboldt — Irrupción en la rnodernidad 1799-1999" [Berlín, 31 de mayo al 3 de junio de 1999]. Diálogo Científico [Tübingen], 8 (2), 113-117.

HETTNER, Alfred. 1927. Die Geographie, ihre Geschichte, ihr Wessen und ihre Methoden. Breslau, Ferdinand Hirt.

HUMBOLDT, Alejandro de. 1989. Carta a su hermano G. de Humboldt [Cumaná, 16 de julio de 1799]. en: Alejandro de Humboldt: Cartas Americanas, $2^{a}$ ed., editadas por Charles Minguet (Caracas: Biblioteca Ayacucho), 13-15.

HUMBOLDT, Alejandro de. 1989. Carta a su hermano G. de Humboldt [Ibagué, 21 de septiembre de 1801]. En: Alejandro de Humboldt: Cartas Americanas, $2^{\mathrm{a}}$ ed., editadas por 
Charles Minguet (Caracas: Biblioteca Ayacucho), 71-75.

HUMBOLDT, Alejandro de. 1989. Cartas Americanas, $2^{\mathrm{a}}$ ed., compiladas por Charles Minguet. Caracas, Editorial Ayacucho.

HUMBOLDT, Alexander von. 1790. Mineraiogische Beabachtungen über einige Basalte am Rhein. Braunschweig.

HUMBOLDT, Alexander von. 1793. Florae fribergensis subterraneas exhibens. Berlin, H. A. Rottman.

HUMBOLDT, Alexander von. 1808-1811. Essai politique sur le royaume de la Nouvelle Espagne. Paris, F. Schoell.

HUMBOLDT, Alexander de. 1814-25. Relation historique du Voyage aux régions equinoxiales du Nouveau Continent, faites en 1799-1804 par A. de Humboldt et A. Bonpland, 3 vols. Paris, F. Schoell (I, 1814); Maze (II, 1819); Smith \& Gide (III, 1825).

HUMBOLDT, Alexander von. 1826. Essai politique sur I île de Cuba. Paris, F. Schoell.

HUMBOLDT, Alexander von. 1845-1862. Kosmos: Entwurf einer physischen Weltbeschreibung, 5 vols. Stuttgart und Tübingen, J.G. Cotta Verlag.

HUMBOLDT, Alexander von. 1978. Ensayo político sobre el reino de la Nueva Espafia, $3^{\mathrm{a}}$ ed. México, Editorial Porrúa. [Primera edición publicada en 1966].

HUMBOLDT, Alexander von. 1982. Alexander von Humboldt in Kolumbien -Alexander von Humboldt en Colombia. Extractos de sus Diarios - Auswahl aus seiner Tagebüchern, preparados por la Academia Colombiana de Ciencias Exactas, Físicas y Naturales, y la Akademie der Wissenchaften der Deutschen Demokratischen Republik. Bogotá, Flota Mercante Grancolombiana.

HUMBOLDT, Alexander von. 1995. Personal narrative of a journey to the equinoctial regions of the New Continent, abridged and trans. by Jason Wilson. Harmondsworth, England, Penguin Books. [Título originalmente publicado en los vols. 28-30 de Relation historique du voyage aux régions équinoxiales du Nouveau Continent, Paris, 1814-1834].

HUMBOLDT, Alexander von [1858] 1997. Cosmos: A sketch of the physical description of the Universe, 2 vol, trans. by E. Cotté. New York, Harper \& Brothers, Publishers. [Las citas del Cosmos en el presente trabajo se refieren a la reimpresión de 1997 de esta versión inglesa, publicada en Baltimore and London, por The Johns Hopkins University Press].

HUMBOLDT, Alexander von. 1998. Ensayo político sabre la isia de Cuba. Madrid, Ediciones Doce Calles.

HUMBOLDT, Al. de, et Bonpland, A. 1805. Essai sur la Géographie des plantes; acompagné D'un Tableau Physique des Régions Equinocciales. Paris, Chez Levrault, Schoell et Campagnie, Libraries.

JAMES, Preston E., and Martin, Geoffrey J. 1981. All possible worlds-A history of geographical ideas, 2nd ed. New York, John Wiley \& Sons.

KOHLHEPP, Gerd. 1999. Alexander von Humboldt en los trópicos del Nuevo Mundo Reflexiones sobre el bicentenario del inicio de su "Viaje a las Regiones Equinocciales" en 1799. Diálogo Científico [Tübingen], 8 (2), 9-24.

LEIGHLY, John, ed. 1967. Land and life: A selection from the writings of Carl Ortwin Sauer. Berkeley, University of California Press.

LEPENIES, Wolf. 1999. Alexander von Humboldt: His past and his present. Berlin, 31 May. Web document: www.hkw.de/english/culture/1999/humboldt/kapitel10/ inks.html.

LIVINGSTONE, David N. 1992. The geographical tradition: Episodes in the history of a contested enterprise. Oxford, UK and Cambridge, Mass.

MINGUET, Charles. 1989. Prólogo. En: Cartas Americanas [de] Alejandro de Humboldt, $2^{\mathrm{a}}$ ed., comp. por Charles Minguet (Caracas, Biblioteca Ayacucho), p.ix.

NICOLSON, Malcolm. 1995. Historical introduction. En: Personal narrative of a journey to the equinoctial regions of the New Continent by Alexander von Humboldt, abridged and translated by Jason Wilson (London, Penguin Classics), ix-xxxiv

OLWIG, Kenneth Robert. 1996. Nature-Mapping the ghostly traces of a concept. En: Concepts in human geography, eds. Carville Earle, Kent Mathewsan and Martin S. Kenzer (Lanham, Maryland, Rowman \& Littlefieid Publishers), 63-96. 
PESCHEL, Oscar. 1877. Abhandlungen zur Erd- und Völkerkunde, 3 vol. Leipzig. [referencia a vol. I: 336-44, citada por Hartshorne 1939: 80]

PESCHEL, Oscar. 1879. Physische Erdkunde. Leipzig, Duncker \& Humblot.

RATZEL, Friedrich. 1882-1891. Anthropogeographie: Vol. I. Grundzüge der Anwendung der Erdkunde auf die Geschichte; Vol. II. Die geographische Verbreitung des Menschen. Stuttgart, Engelhorn.

RATZEL, Friedrich. 1897. Politische Geographie. Munchen.

RICHTHOFEN, Ferdinand von. 1883. Aufgaben und Methoden der heutigen Geographie. Leipzig, Akad. Antrittsrede.

RUPKE, Nicolaas A. 1997. Introduction to the 1997 [Cosmos] edition. En: Cosmos: A sketch of the physical description of the Universe, vol. 1, by Alexander von Humboldt, trans. by E.C. Otté (Baltimore and London, The Johns Hopkins University Press), vii-xlii. [cf. Humboldt, 1997, supra]

SCURLA, Herbert. 1982. Alexander von Humboldt: Eine Biographie. Düseldorf, Claassen.

ZÚÑIGA, Neptalí. 1975. Humboldt y el americanismo. Quito, Universidad Central del Ecuador. 